\title{
Aerodynamical Performance Decay Due to Fouling and Erosion in Axial Compressor for GT Aeroengines
}

\author{
Giovanni Maria De Pratti* \\ "La Sapienza" University of Rome, DIMA
}

\begin{abstract}
The ingestion of solid abrasive particles and/or foulants causes erosion of the compressor blades, resulting in a considerable reduction in the performance and working life of aviation/heavy duty GT and an increase in fuel consumption. The geometry variation at the Leading Edge (L.E. blunting) and Trailing Edge (T.E. thickness reduction), together with the general increase of airfoil surface roughness, depends on the characteristics of the incident particles, the geometry and the materials of the blade cascade, the dynamic parameters of the particles and on the type of impact. In order to rectify this degradation in performance, it is therefore necessary to re-profile the blades with machining that is highly critical for the performance of the engine, the life of the compressor blades and for maintenance costs. In order to determine an optimum and cost effective process of reprofiling, a series of tests reproducing the corresponding models of flow have been carried out on the Water Table Test Bench using Lamb's hydraulic analogy relative to profiles of the VII and VIII stage HP of the compressor of the GT CF6-50 (G.E. Co.). The tests were carried out both on the isolated airfoil profile and on the blade cascade and both in the original conditions, at varied geometry (because of erosion and/or fouling) and after re-profiling. The trajectories of the particles have been visualised in several ways (like a false color photographic procedure), confirming results reported by various authors related to the model of impact and erosion. Particularly in the case of the dust aspiration during the arrival phase on the deck of an aircraft carrier. The test results have been discussed and compared with those available in scientific literature.
\end{abstract}

\footnotetext{
*Corresponding Author: giovannimaria.depratti@uniromal.it
} 


\section{Overview}

The performance of the axial compressor blades of gas turbine engines basically depends on the shape of the profile of the airfoil and especially on the design of its leading edge (both shape and incidence angle).

According to [2], "...there is a small correlation between the chord length and the geometry of the blade. The radius of the leading edge (L.E.R.) and its incidence have a larger influence on performance than the chord length".

The shape of the blades, optimized during the design phase and the construction of the compressor, undergo significant changes during operation; possible flaws or modifications that can arise during operation cause a drop in aerodynamic performance which then results in an increase in fuel consumption and a lower engine "efficiency", as well as increasing the maximum temperature of the cycle (E.G.T.).

Furthermore, during a quality inspection, the "damaged" blades can be discarded, which results in an increase in costs and a loss in materials. There are a number of types of imperfections and variations of the profile of the blade sections, described in detail in scientific studies [cfr. in [2], [22], [12], [23], [6], [7], [15], [14] and [16], such as:

1) leading edge erosion (blunting and variation in the incidence angle and in the leading edge radius);

2) thinning of the blade trailing edge;

3) variation of the blade trailing edge angle;

4) increase in surface roughness

5) camber variation.

Erosion can reach significant values and effects depending on the large amount of dust contained in the high inlet flow rate. These dust particles can be of various types, from sand to ash of volcanic origin, or salt spread on the icy runways etc. On the other hand, it is not only dust that causes damage to the turbine and compressor blades. In general, according to [14], a drop in performance of the gas turbines is due to a series of various causes:

a) fouling (caused by minute dusts: pollen, salt spray and insects which are deposited on the surfaces);

b) erosion (of the blade surface caused by solid particle ingestion);

c) increase of the gap at the tip of the blade (caused by solid particle ingestion); rain drop ingestion;

d) damage from foreign objects (FOD) (caused by hail, gravel from the runway and avian ingestion. 
In a previous paper [10] some aspects shown by [7], [8], [14], [22] and [15], and, finally, they have recognised as a number of aircraft incidents and failures caused bay solid ingestion of various kinds, an indication that the problem has repercussions on the safety and reliability of the use of aviation gas turbine engines (flight safety). The vulnerability of high performance aircraft and of gas turbines of stationary power installations to particles carried in the intake airflow is a highly serious issue which concerns both manufacturers and users of these turbo machines, regarding construction with suitable materials for manufacturers, and the fine tuning of adequate procedures of maintenance and restoring for both manufacturers and users. The damage also has complex economic implications concerning both management and maintenance: regarding plant management, [22] reports, for example, that the leading edge blunting can cause an increase in fuel consumption of $0.38 \%$, while the increase in surface roughness causes an extra $0.19 \%$ increase in fuel consumption. Data from ICAO and IATA shows considerable sensitivity on the part of airline carriers to the problem of the weight of fuel costs on airline management, even when low. [9] reports that for a "typical airline" the percentage rate of the total operating costs of fuel and lubricants is $13.9 \%$, while the cost of the fleet's aircraft maintenance is $10.9 \%$. Clearly erosion and the subsequent performance degradation of the compressors and consequently of gas turbine engines, is connected to this argument of operating efficiency and of maintaining the engines in flight as long as possible and in safe conditions; and it is equally clear that a reduction in fuel consumption and maintenance costs can benefit the carrier's budget.

Starting from the year 2000 (source: IACO) the critical situation of a number of airlines has also been attributed to fuel costs and aircraft maintenance costs, besides the costs of employees.

According to [16], in a typical gas turbine power plant, 50-70\% of operating and maintenance costs comes from repairing and substituting the major components in the hot section of the gas turbine, and we know that the deterioration of the blades also causes an increase in maximum temperature (E.G.T.). [16] also reports that damage caused by FOD accounts for a minimum of $10 \%$ and maximum of $30 \%$ of parts to be replaced, and causes various degrees of damage classified as: "minor", "medium" and "major". This broad overview gives a very clear picture of the number of damages to the compressor blades and the wide range of situations to be dealt with. Stationary applications benefit from complex filter devices but, as [12] [13] [20] and [21] report, particles with a diameter of under $15 \mu \mathrm{m}$ are difficult to separate in cyclones. Both researchers cite Montgomery \& Clark's data from 1962, according to which, particles with a diameter under $5 \mu \mathrm{m}$ can cause serious losses during the operating life of gas turbines. 


\section{Reference Data}

The range of the most commonly used gas turbine engines is very wide and varied and in this regard [12] compiled a table, reproduced below (Table 1), which records the sectors covered by various manufacturers. Regarding these small aeronautical turbines, [1] states that "...the performance...[of these machines]...can be much more susceptible to fouling than their industrial counterparts...".

Table 1.

\begin{tabular}{|c|c|c|}
\hline Manufacturer & Unit & \% of Market \\
\hline ASEA Brown Boveri GT - 8,9,11,13 & 550 & 10 \\
\hline GE. Co Frame 5, 6, 7,9 & 3,500 & 64 \\
\hline Siemens/KWU V64, 84, 94 & 150 & 3 \\
\hline Westinghouse W 171-501 & 1,300 & 23 \\
\hline Total (the values are approximate) & 5,500 & 100 \\
\hline
\end{tabular}

[5] cites studies carried out on the P/W TF33P11A turbofan and the P/W J57-19W turbojet, while [19] cites studies carried out on the TF-39 and the F-100, two engines for military aircraft (for transport and combat respectively). [10] cites some studies carried out on the JT8D and [14] refers, on the other hand, to those on an automotive engine of the Chrysler Corporation. [1] carried out their evaluations of two common pipeline engines, the G.E. LM2500 and the Solar Centaur. [14] report data regarding the Pratt \& Whitney JT9D and the General Electric Company CF6. The latter, the G.E. CF6-50, is the gas turbine engine that we have taken as a point of reference for our investigation. It is a turbofan installed in a "wide body" aircraft such as the Boeing 747 and the Airbus A300, which are widely used aircraft and are still used by numerous airline carriers. Some suitably modified versions have also been used in stationary applications. The full name of the engine is GE CF6-50 High by-pass Turbofan Engine and its reference details are shown in Table 2.

Table 2.

\begin{tabular}{|c|c|}
\hline Thrust & $50,000 \mathrm{lb}(222,221 \mathrm{~N})$ \\
\hline Total Lenght & $246.3 \mathrm{in}(6.256 \mathrm{~m})$ \\
\hline Total Weight & $8,756 \mathrm{lb}(3,979.3 \mathrm{~kg})$ \\
\hline Direction of Rotation & Clockwise \\
\hline
\end{tabular}

The engine has a low pressure compressor (LPC) with a fan and booster, and a high pressure compressor (HPC) composed of 14 stages, of which the first seven have adjustable statoric guide 
vanes). It has a pressure ratio at 29.3. This compresses the air up to $2.758 \mathrm{MPa}$ before it is sent to the combustion chamber. Regarding stages 7 and 8, especially stage VIII, of the high pressure compressor, tests have been carried out to establish the aerodynamic performance of the isolated airfoil profile in original profile conditions, as well as worn and restored in at least two modes, that is through grinding and in similitude conditions. The type of isolated airfoil profiles has been derived from the original designs of the engine and its better designation may be Gottinga profiles 427 or 436. In any case, although the exact profile designations are unknown, they have been reproduced on the basis of numerical data tabulated on the original designs of the engine included in the manual as in [4]. As the official NACA designation of the profiles is not available, it has not been possible to take full advantage of the performance data from literature, however, having obtained some typical characteristics of the original 'family' from the section profiles, from numerical data, and from other texts (see in [9]), it was possible analyse about isolated profile performance and about the relative cascade for the parent profiles of the object of this investigation. The airfoil profile which is the object of this study (see Fig. 1) is thus that of the blades of stage 7 and 8 of the CF6-50 engine and it has been reconstructed, as previously mentioned, on the basis of the manufacturer's tables.

Figure 1: Test Airfoil Profile: Original And Worn Versions
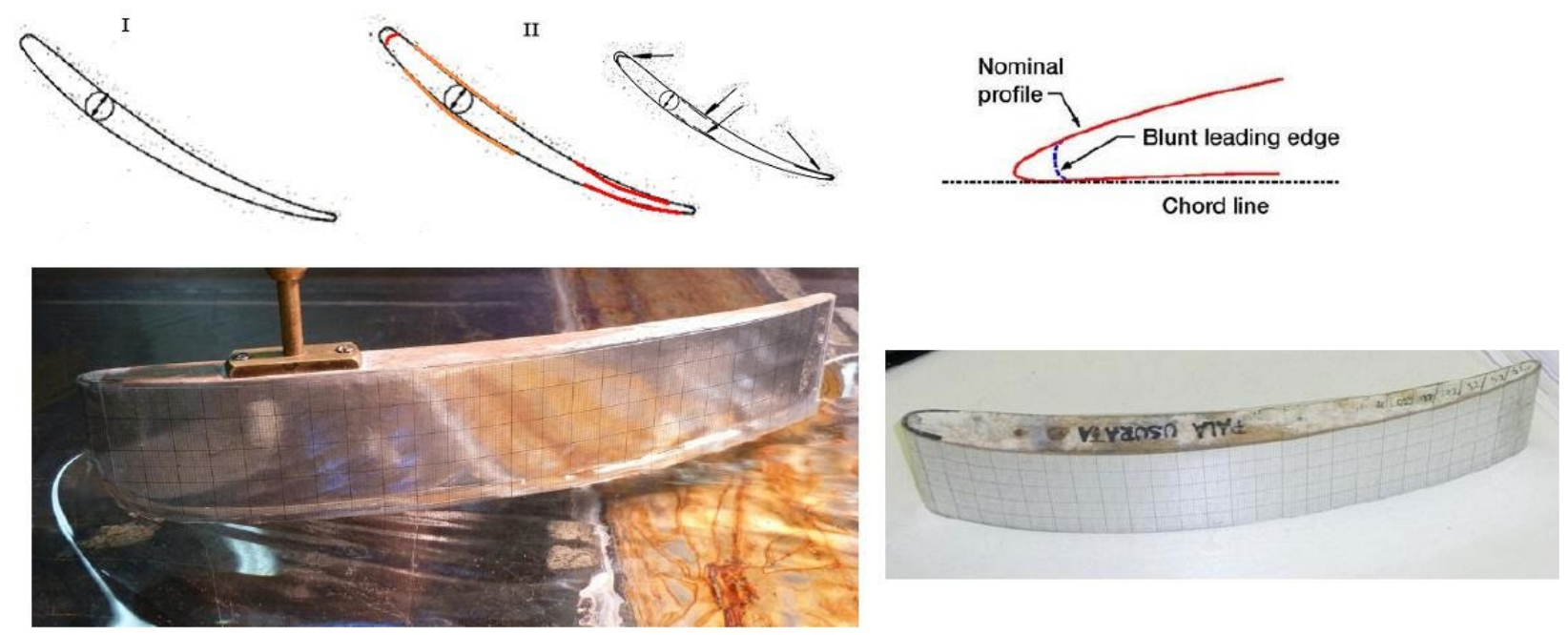

The worn airfoil profile was reconstructed modifying the Leading Edge Roughness (LER) and the chord according to data that predict the surface wear for the blades according to the operating life of the engine, as well as through data supplied from those responsible for maintenance.

It is known, from the manufacturer's data, that erosion causes an increase in LER equal to 0.0002 inches every 1,000 flight hours, and a chord reduction of 0.003 inches every 1,000 flight hours. In our case we have assumed that the profile was extracted from an engine with 6,000 flight hours, corresponding to a time interval related to the aircraft engine's first service, as 
reported by the engine maintenance staff. Having taken this flight time period into consideration is in line with the assumptions of other researchers that took 6,000-8,000 hours service as a time reference to quantify the effects of erosion, and actually for the CF6 engine (see in [14]).

Given the small size of the blades and the worn parts, in order to highlight the various effects experienced, the models were magnified so that the blades tested on the Water Table had a chord on a scale of 8.682:1; in choosing the size of the profile, we tried to avoid interference phenomena with the walls of the section tested. Thus instead of the original profile of $24.95 \mathrm{~cm}$, the following sizes were used for the profiles: worn $24.55 \mathrm{~cm}$, restored by grinding (SWECO) $24.45 \mathrm{~cm}$ and restored in similitude $24.3 \mathrm{~cm}$. The efflux around the profile was examined at a Mach number equal to around 0.86, and a Reynolds number between $8.16 \times 10^{6}$ and $8.33 \times 10^{6}$. These values are those resulting from a flight quota of $10,668 \mathrm{~m}$, with a rotation speed at the tip of the blade $u=360 \mathrm{~m} / \mathrm{s}$ and a relative speed $w_{1}=387.96 \mathrm{~m} / \mathrm{s}$ calculated at around $3 / 4$ of the blade spanwise and a degree of reaction equal to 0.668 and with an inlet temperature at the $8^{\circ}$ stage $\mathrm{T}=500 \mathrm{~K}$. The Reynolds number range explored is of the same order of magnitude, even if inferior, as that referred to by [6] and an agreement was found with the relationship referred to by them and attributed to Hudson dated 1991, according to which the efficiency ratio is proportional to $(\mathrm{Re}) 0.038$.

\section{Analysis of the flow of foulant or abrasive particles ingested by the engine}

As mentioned also in [10], a considerable reduction in the performance and operating life of GT for stationary and aeronautical applications is caused by erosion of the blade surfaces of the compressor, due to solid particle ingestion and fouling caused by the depositing of various materials ingested with fouling characteristics and/or by adsorption properties towards the metal surfaces. The question has been described in [10] in the following terms:

I)description of the inlet flow with analysis of the mass and volume content of the abrasive and/or foulant particles and their characteristics;

II) description of the abrasive phenomenon by applying the model of impact;

III) correlation between the time of operation and the change in blade geometry:

IV) reproduction of the operating conditions in similitude to reproduce the flow of abrasive and foulant particles;

V) comparison of the trajectories of the particles around the profiles and through the cascade to verify the validity of the model of impact and abrasion. Through the studies of published authors ([10], [18] and [3]) it was possible to identify models to characterize the inlet flow and the characteristics of the particle-profile interaction, the result of which consists in the change of the blade surfaces, previously mentioned on various occasions. The description of the characteristics 
of these airborne particles, which give rise to a mixed liquid/solid flow carried in the air, had been shown in a prevoius paper [10] as in the following equations. The first hypothesis (see in [18]) is represented by a 'continuum having a local mass density per unit of volume'. Consequently, we have the approach suggested by [10] in which $\mathbf{X}$ is position, $\mathbf{f}(\mathbf{x}, \mathbf{v}, \mathbf{t})$ is the statistic distribution about particles, whit $\mathbf{x}$ the spatial coordinate, $\mathbf{v}$ the efflux velocity and $\mathbf{t}$ the time, with $\mathbf{f}(\mathbf{x}, \mathbf{v} ; \mathbf{t}) \boldsymbol{\delta} \mathbf{x} \boldsymbol{\delta} \mathbf{v}$ as the number of particles which at the time $t$ have a position (coordinate) between $\mathrm{x}$ and $\mathrm{x}+\delta \mathrm{x}$ and whose velocity falls between $\mathrm{v}+\delta \mathrm{v}$. If $(\delta \mathrm{x}, \delta \mathrm{v}) \rightarrow 0$ the volume of the phase contains a sufficient number of particles to enable the statistic distribution to be used. To improve the description it is useful to introduce the "mean radius" $\left\langle\mathrm{r}_{0}\right\rangle$ and its variance $\left\langle\Delta \mathrm{r}_{0}^{2}\right\rangle$ with respect to the population of particles and a function of integral distribution in a random but finite volume, $V_{0}\left[\mathcal{X}_{0}(t)\right]$, around a physical position $\mathrm{x}_{0}$, which can thus be written:

$$
\Phi_{0}\left(r, x_{0} ; t\right)=\int_{V_{0}} f(r, x ; t) d V_{0}(x)
$$

Where the integral function $\Phi_{0}$ represents the number of particles which at the time $t$ are within volume $\mathrm{V}_{0}$ around $\mathrm{x}_{0}$ and whose average radius is included in the elementary interval $\delta \mathrm{r}$. Each dimension or average property $(\Psi)$ related to the particles can therefore be expressed as:

$$
\psi_{0}\left(r, x_{0} ; t\right)=\frac{1}{\Phi_{0}\left(r, x_{0} ; t\right)} \int_{V_{0}} f(r, x ; t) \psi(r, x ; t) d V_{0}(x)
$$

Therefore, for example, the "average radius" of the particles which participate in the interaction can be written:

$$
\begin{gathered}
\left\langle r_{0}\right\rangle\left(x_{0} ; t\right)=\frac{1}{N_{0}\left(x_{0} ; t\right)} \int_{0}^{\infty} r \Phi_{0}\left(r, x_{0} ; t\right) d r \\
\left\langle\Delta r_{0}^{2}\right\rangle\left(x_{0} ; t\right)=\frac{1}{N_{0}\left(x_{0} ; t\right)} \int_{0}^{\infty}\left[r-\left\langle r_{0}\right\rangle\left(u_{0} ; t\right)\right]^{2} \Phi_{0}\left(r, x_{0} ; t\right) d r
\end{gathered}
$$

where $\mathbf{N}_{\mathbf{0}}$ is the number of particles in the chosen volume and $\mathbf{u}_{\mathbf{0}}$ is the velocity of the particles around $\mathbf{x}_{\mathbf{0}}$ which are simply transported by the fluid which carries them. Since no force has been introduced, there is no reason to maintain that a differential distribution of the velocity of the fouling or abrasive particles exists. The second point to be examined is the characterization of fouling and abrasion. With regards to fouling and abrasion, as shown in [10] and [3], we can apply the following model of impact solid airborne particles/surface:

$$
D_{e l i}=\int_{e l} \sigma_{i j} \varepsilon_{i j} /\left(E_{f r} S_{e l}\right) d V_{e l}
$$

where $\varepsilon_{\mathrm{ij}}$ and $\sigma_{\mathrm{ij}}$ represent the tensor of deformation and the tensor of stress respectively, while $\mathbf{E}_{\mathrm{fr}}$ is the fracture energy of the material (of the blades for example) and $\mathbf{S}_{\mathbf{e l}}$ the surface of impact. Note that the fracture energy, $\mathbf{V}_{\text {el }}$ being the volume of the single element subjected to impact, is expressed: 


$$
E_{f r}=\int_{V_{e l}} \sigma_{i j} \varepsilon_{i j} d V_{e l}
$$

From this formula the rate of erosion can be deduced, which, with $\mathbf{M}_{\mathbf{p}}$ being the mass of the particles and $\mathbf{n}_{\mathbf{p}}=\mathbf{N}_{\mathbf{0}}$ being the number of particles with erosive characteristics, is equal to:

$$
E_{\text {eros_rate }}=\rho_{t}\left(\frac{\sum D_{\text {eli }} m_{\text {eli }}}{n_{p} M_{p}}\right)
$$

where $\mathbf{m}_{\text {eli }}$ is, obviously, the mass of the single element of the blade cascade subject to impact with the flow of abrasive particles. In (7) $\rho_{t}$ represents the density of the material which forms the target of the impact. The impact has been outlined in Fig. 2.

Figure 2: Diagram of the Interaction of the Particle-Blade Cascade Impact as Proposed by [3]
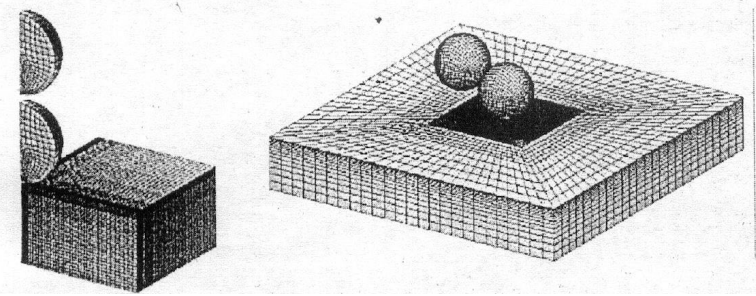

On the basis of the damage function and the data provided by the maintenance staff of the CF6 engine, we can deduce two relationships which empirically explain the amount of geometry variation which is a consequence of the abrasion according to the outlined diagram of impact:

$$
\begin{aligned}
& \Delta_{(-)} \mathbf{c}=\boldsymbol{K} \text { a T }(\mathrm{mm} / \text { flight hours }) \\
& \Delta_{(+)}(\text {LER })=\text { H b T (mm/flight hours) }
\end{aligned}
$$

which represent the decrease in chord length (c) and the increase in the radius at the L.E. (LER) respectively. The coefficients $\mathrm{a}, \mathrm{b}, \mathrm{K}$ and $\mathrm{H}$ are derived from experience until they can be modelled from similitude analysis. Coefficients "a" and " $b$ " especially show the rate of change that is a consequence of wear in non-aggressive environments, while coefficients " $\mathrm{K}$ " and " $\mathrm{H}$ " take into account the environment operating conditions and show how normal wear can worsen because of the effects of the characteristics of aggression of the particles of impact.

In the case which is the object of this present study, the data recorded below in Table 3 was obtained on the basis of statistics compiled by staff in charge of maintenance.

Table 3.

\begin{tabular}{|l|l|l|}
\hline Coefficient & \multicolumn{1}{|c|}{ Value } & \multicolumn{1}{c|}{ Unit } \\
\hline $\mathrm{a}$ & $7.62 \cdot 10 \mathrm{exp}-5$ & $\mathrm{~mm} /$ flight hours \\
\hline $\mathrm{b}$ & $5.08 \cdot 10 \mathrm{exp}-6$ & $\mathrm{~mm} /$ flight hours \\
\hline $\mathrm{K}$ & $1-1.5$ & nondimensional \\
\hline $\mathrm{H}$ & $1-1.15$ & nondimensionale \\
\hline
\end{tabular}




\section{Test Equipment}

The profiles, which were reproduced in similitude and on a larger scale, were tested using Lamb's Hydraulic Analogy on the Water Table Test Bench at the 'Dipartimento di Ingegneria Meccanica ed Aerospaziale' at the University of Rome. As known, the rules shown in Table 4 below are valid for the analogy. As known, in the Hydraulic Analogy, the Reynolds number (Re) cannot be reproduced in the same way as the Mach number, that is equal to the Froude number. However, on the basis of an important contribution by [17] it has been shown through experiments that the efflux in the air and on the Water Table behave in the same way even if the Re numbers are different.

Table 4: Characteristic Parameters of Lamb's Analogy

\begin{tabular}{|c|c|}
\hline Gas Flow & Water Flow \\
\hline Pressure Wave Speed: $\mathrm{c}=(\mathrm{KRT})^{\wedge} 0.5$ & Gravity Long Wave Speed $\mathrm{a}=(\mathrm{gh})^{\wedge} 0.5$ \\
\hline Mach Number: $\mathrm{Ma}=\mathrm{u} / \mathrm{c}$ & Froude Number: $\mathrm{Fr}=\mathrm{u} / \mathrm{a}=\mathrm{u} /(\mathrm{gh})^{\wedge} 0.5$ \\
\hline Density Ratio: $\rho / \rho 0$ & Water Heights Ratio: $\mathrm{h} / \mathrm{h} 0$ \\
\hline Pressure Coefficinet Ratio: $\mathrm{p} / \mathrm{p} 0$ & Water Heights Square Ratio: $(\mathrm{h} / \mathrm{h} 0)^{\wedge} 2$ \\
\hline Temperature Ratio: $\mathrm{T} / \mathrm{T} 0$ & Water Heights Ratio: $\mathrm{h} / \mathrm{h} 0$ \\
\hline
\end{tabular}

Figure 3: Diagram Showing The Evaluation Of Error Using The Analogy.

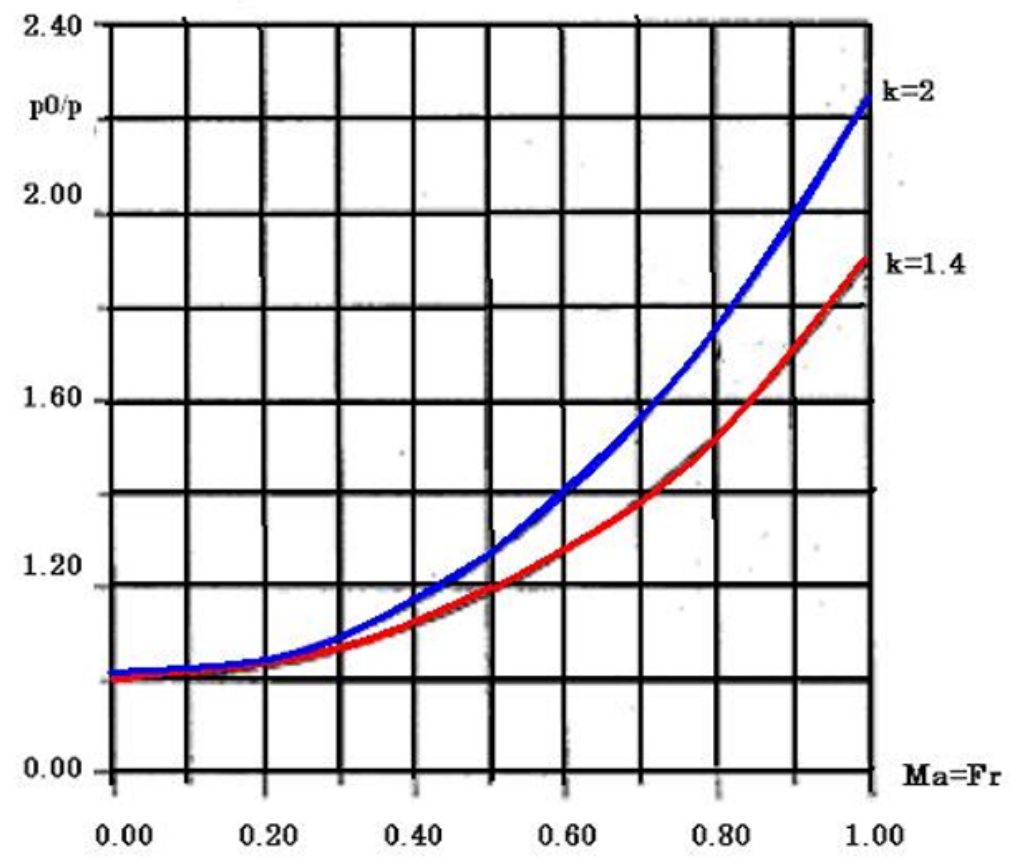


The tests, as established by [11], were carried out within the Re range in which the Strouhal number is kept independent from Re's variation, with the undoubted benefit of being able to take advantage of the lengthening of non-stationary phenomena made possible by the Analogy. In Lamb's Analogy, the exponent $\mathrm{k}$ of the adiabatic process is equal to 2 and not to 1.4 , thus, by approximating the efflux in the air with that in the "hydraulic gas" an error is introduced which increases with the Ma number. This error is between $4.5 \%$ for $\mathrm{Ma}=\mathrm{Fr}=0.4$ and $13.3 \%$ approximately, where $\mathrm{Ma}=\mathrm{Fr}=0.8$ as shown in Fig. 3. Specific corrections have been taken into account such that the chord, for some attack angles, becomes of the same order of magnitude as the flow free section. The above mentioned corrections are provided (in terms of the lift coefficient $\mathrm{c}_{\mathrm{L}}$ ), with reference to the chord $\mathrm{c}$ and length of the test section $\mathrm{h}$, from:

$$
\Delta c_{L}=c_{L} \cdot\left[-\frac{\pi^{2}}{48} \cdot\left(\frac{c}{h}\right)^{2}+\frac{7 \cdot \pi^{4}}{3072} \cdot\left(\frac{c}{h}\right)^{4}\right]
$$

\section{Tests Carried Out}

Essentially two types of tests were carried out: those on the isolated profile and those on the profile cascade. In both cases tests were then carried out both on profiles in the original conditions and with varied geometry and then, finally, with geometry restored through grinding and in similitude conditions. Test outlines are shown in Figures 4 and 5, while the following typical equation was used to calculate the lift coefficient:

$$
c_{L}=\frac{\cos \alpha}{2 \cdot F r^{2} \cdot h_{\infty}^{2} \cdot l} \cdot \sum_{i}\left[\left(h_{i}^{2}+h_{i+1}^{2}\right)_{\text {sup }}-\left(h_{i}^{2}+h_{i+1}^{2}\right)_{\text {inf }}\right] \cdot X_{i}
$$

where $\mathbf{l}$ is the chord length, $\boldsymbol{\alpha}$ the angle of incidence, $\mathbf{h}$ the height at the sides of the profile and $\mathbf{X}_{\mathbf{i}}$ the points of measurement along the chord.

Figure 4: Isolated Profile

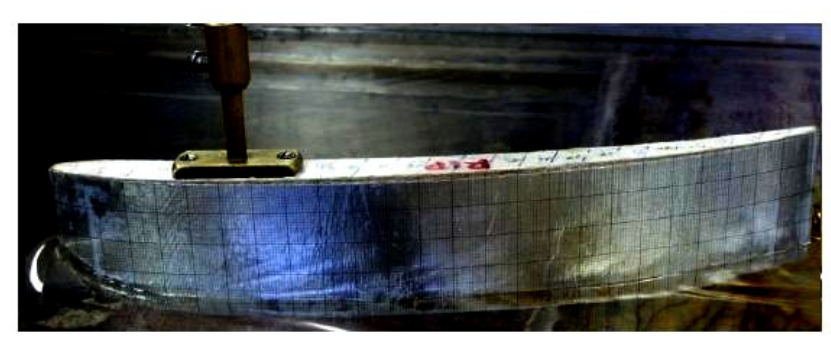

Figure 5: Cascade

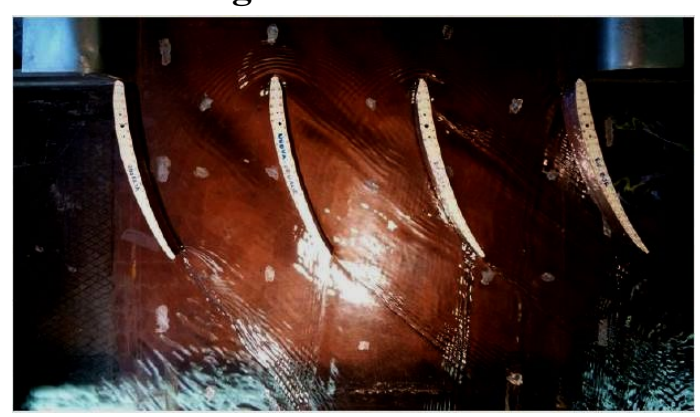

Table 5 shows the test results from the isolated profile in various conditions at corresponding various values of $\mathrm{Ma}=\mathrm{Fr}$, respectively, at various selected operating conditions.

As seen from the data in Table 5, at cruising speed, when passing from the original profile to the worn one there is a reduction of $6.30 \%$ in the lift coefficient. The surface grinding enables a recovery of only $1 \%$, while with the restoration in similitude there is, on the contrary, an increase 
in the lift coefficient in comparison with the original conditions. This paradox is attributed to the fact that with the restoration in similitude there is a noticeable reduction of the chord compared to the original. Concerning the tests on the cascade, after introducing Weinig's $\mathrm{K}$ coefficient:

$$
\frac{C_{L S}}{C_{L i s}}=K
$$

with its well-known parameters, the results in Table 6 lead to the conclusion that the average value of $\mathrm{K}$ is equal to 0.72 compared to 0.613 which would be obtained from Weinig's diagrams.

Table 5: Airfoil Test Results (Lift Coefficients) (Fr=Ma in the Analogy)

\begin{tabular}{|c|c|c|c|c|c|}
\hline Alpha & $\mathrm{F}_{1}=0.6$ & $\mathrm{~F}_{1}=0.7$ & $F_{1}=0.8$ & $F_{1}=0.86$ & Suface Condition \\
\hline 0 & 2.363 & 1.944 & 1.614 & 1.476 & Original \\
\hline 0 & 2.164 & 1.573 & 1.402 & 1.383 & Worn \\
\hline 0 & 2.147 & 1.663 & 1.447 & 1.397 & Grinded \\
\hline 0 & 2.200 & 1.758 & 1.504 & 1.529 & Restored in Similitude \\
\hline \multicolumn{6}{|c|}{ N.B.: When $M a=F r$ there are different engine rpm in different flight conditions } \\
\hline & $\mathrm{Ma}=0.6$ & low rpm & & & \\
\hline & $\mathrm{Ma}=0.7$ & low rpm & & & \\
\hline & $\mathrm{Ma}=0.8$ & middle rpm & & & \\
\hline & $\mathrm{Ma}=0.86$ & cruise rpm & & & \\
\hline
\end{tabular}

The fact that the lift coefficient of the profiles in cascade is lower than that of the isolated profile is due to the fact that the angle of pitch is around $43^{\circ}$, less therefore than the limit set at $45^{\circ}$, the value at which both the isolated profile and the cascade profile have the same lift. The stagger angle was about $16.5^{\circ}-18.5^{\circ}$, while $t / c$ ratio is about $0.79-0.55$ in various tests.

Finally, the result obtained from the incident particle trajectories is shown in Table 6 . The incident particles were visualized using an insemination of tobacco particles in the upstream water current.

Table 6: Test Results From The Cascade Compared To Those From The Isolated Profile (Lift Coefficients) ( $\mathrm{Fr}=\mathrm{Ma}$ In The Analogy)

\begin{tabular}{l|c|c|}
\hline Cascade alpha $=\mathbf{0}$ & $\mathbf{F r}=\mathbf{0 . 6}$ & $\mathbf{F r}=\mathbf{0 . 7}$ \\
\hline original & 1.715 & 1.397 \\
\hline worn & 1.538 & 1.127 \\
\hline Isolated profile alpha=0 & & \\
\hline original & 2.363 & 1.944 \\
\hline worn & 2.164 & 1.573 \\
\hline
\end{tabular}

The trajectories shown in Fig. 6 appear to agree with those recorded by other authors as do the results from the aforementioned scientific literature. Unfortunately the only shortcoming is due 
to the fact that it has not yet been possible to carry out the test with the tracer particles properly scaled down for the experiment in similitude conditions.

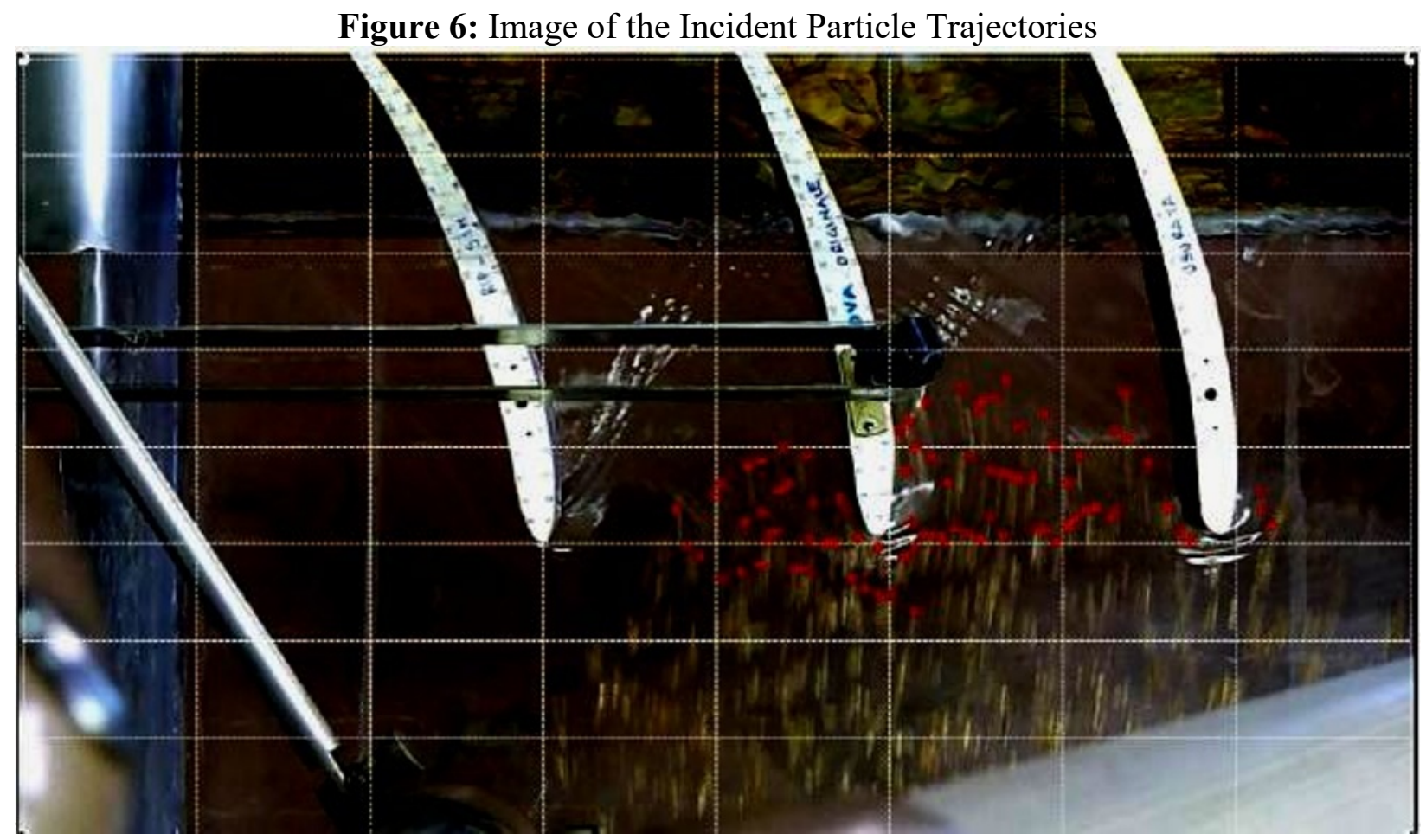

However, it is believed that if another type of tracer is used (of the type used in the Particle Image Velocimetry technique) or if the tobacco is refined further, it should be possible to remedy this problem. Although the scaling problem exists, the results are not only qualitative as in comparison with data in [4], [10] and [1].

\section{Analysis of Trajectories of Incident Particles}

FIGURE 7

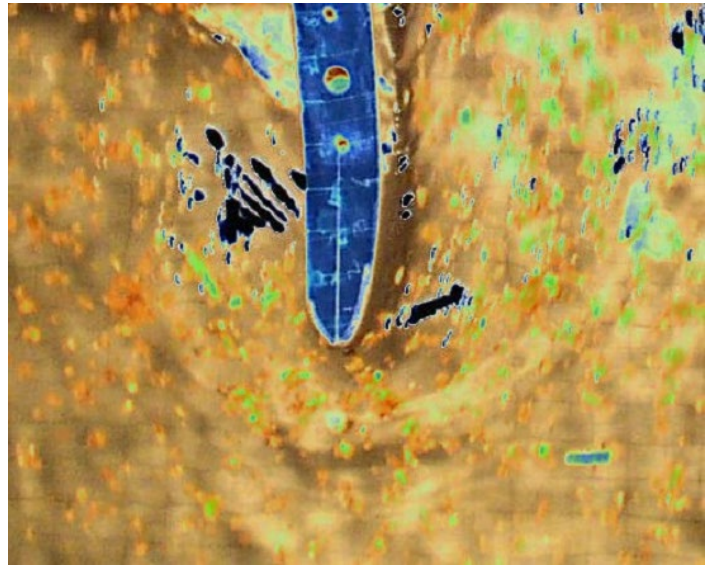

FIGURE 8

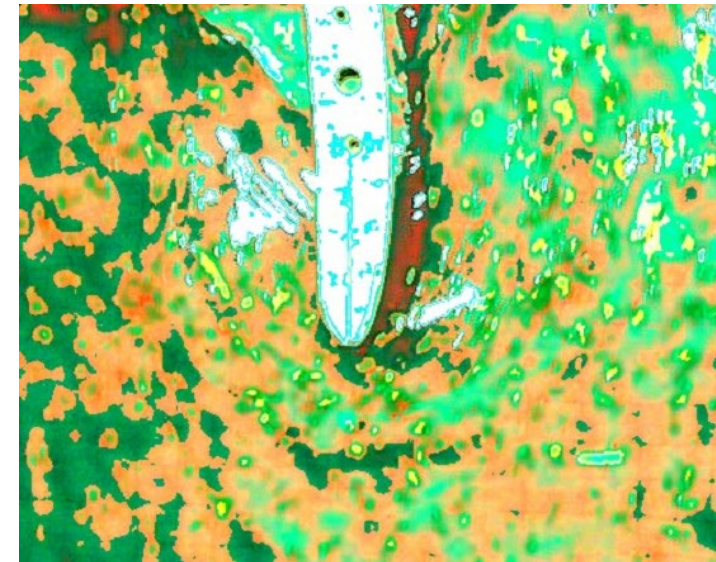


In the Figs. 7 and 8 the specific fields of motion around a blade are shown by the false colours technique to underline the impacting flows, the different wind speeds and the interactions between impacting particles (with their trajectories) and the blade.

The pictures have been realised with a false colours photographic technique and show the trajectories of foulant particles. In Figs 10 and 11 the impact of particles with blade surface is explained in all the possible kinds.

\section{Figure 10}

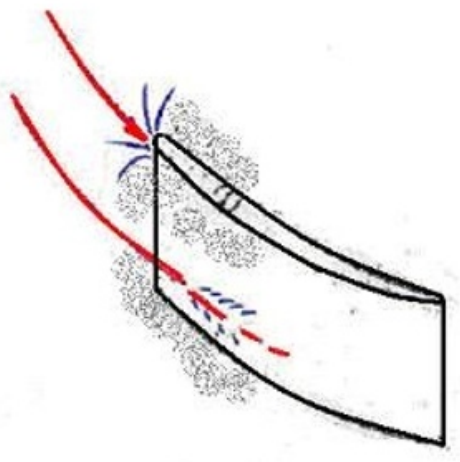

Legend

Flow lines

Particles cloud

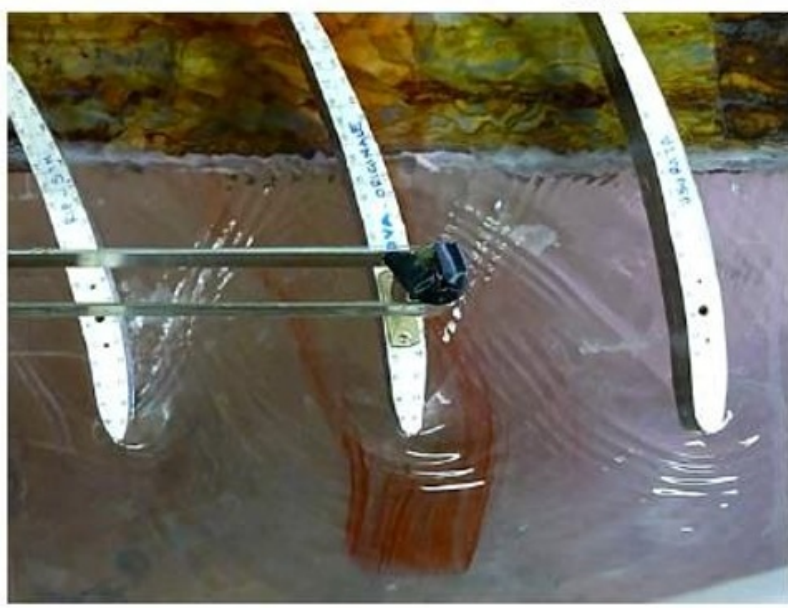

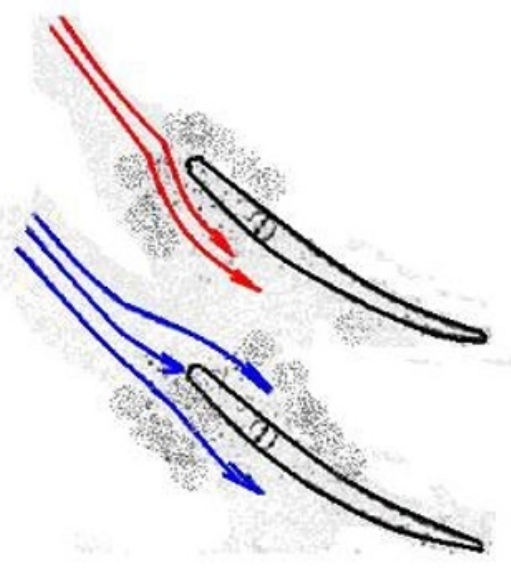

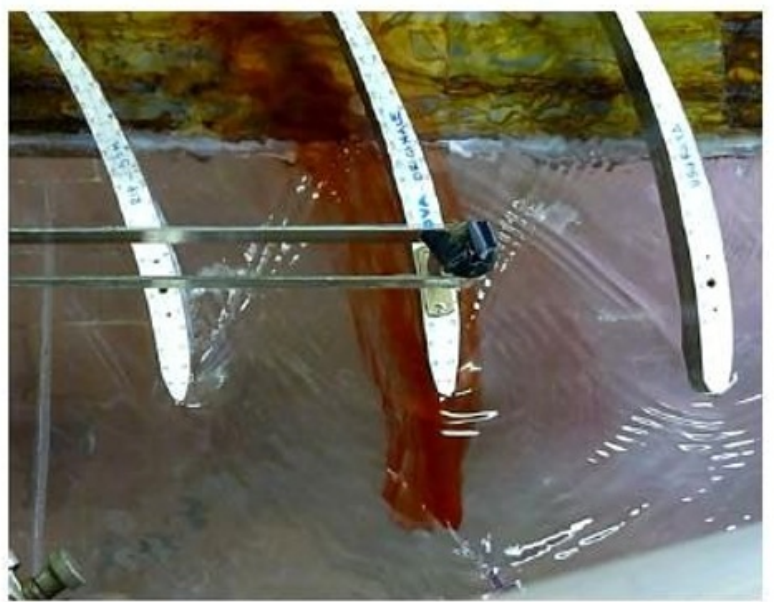

The conditions exposed in previous Figs. 8, 9, 10 and 11, as reported by [19], may be realised in situations as in Fig. 12 where is shown an Harrier in arrival phase on the deck of an aircraft carrier. 


\section{Figure 11}

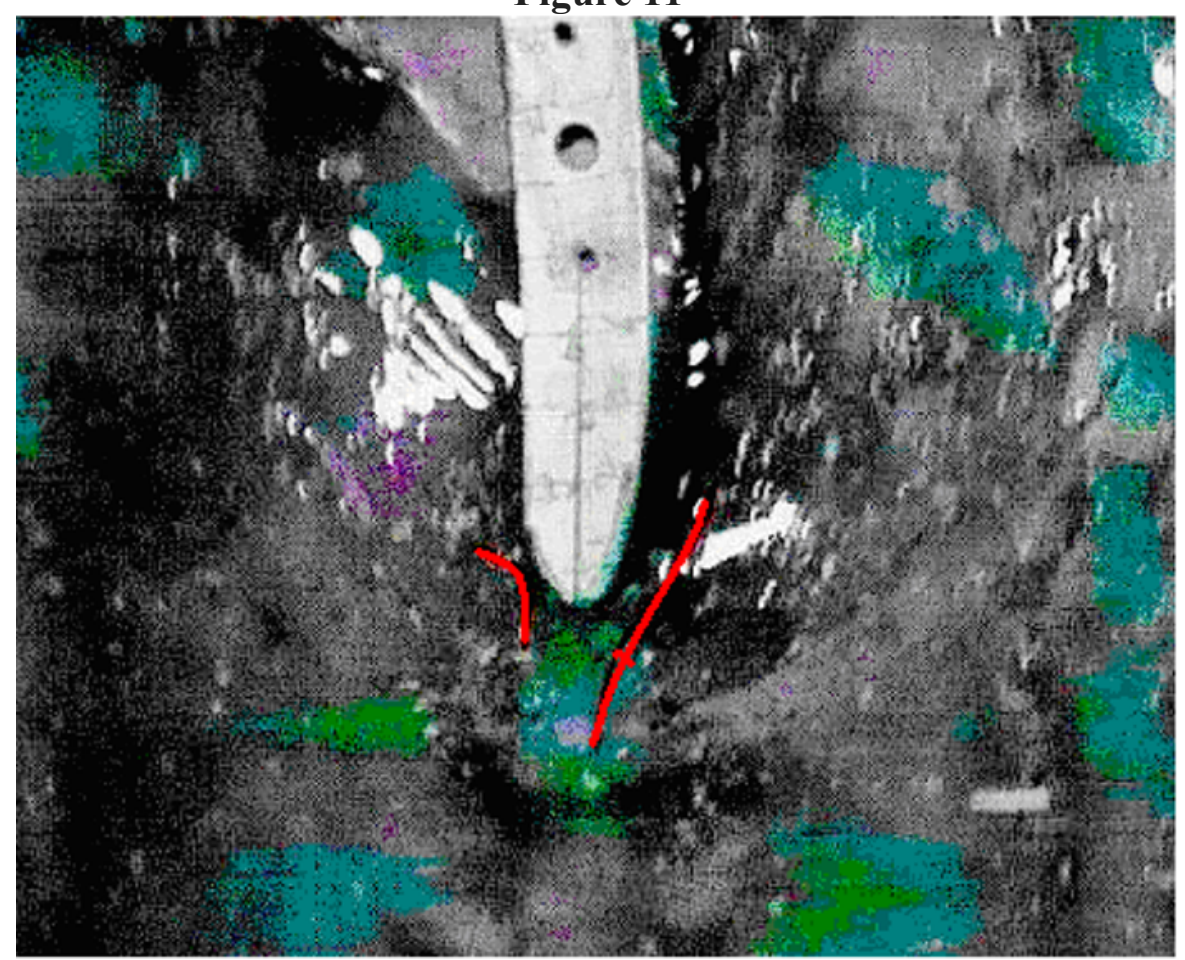

Figure 12
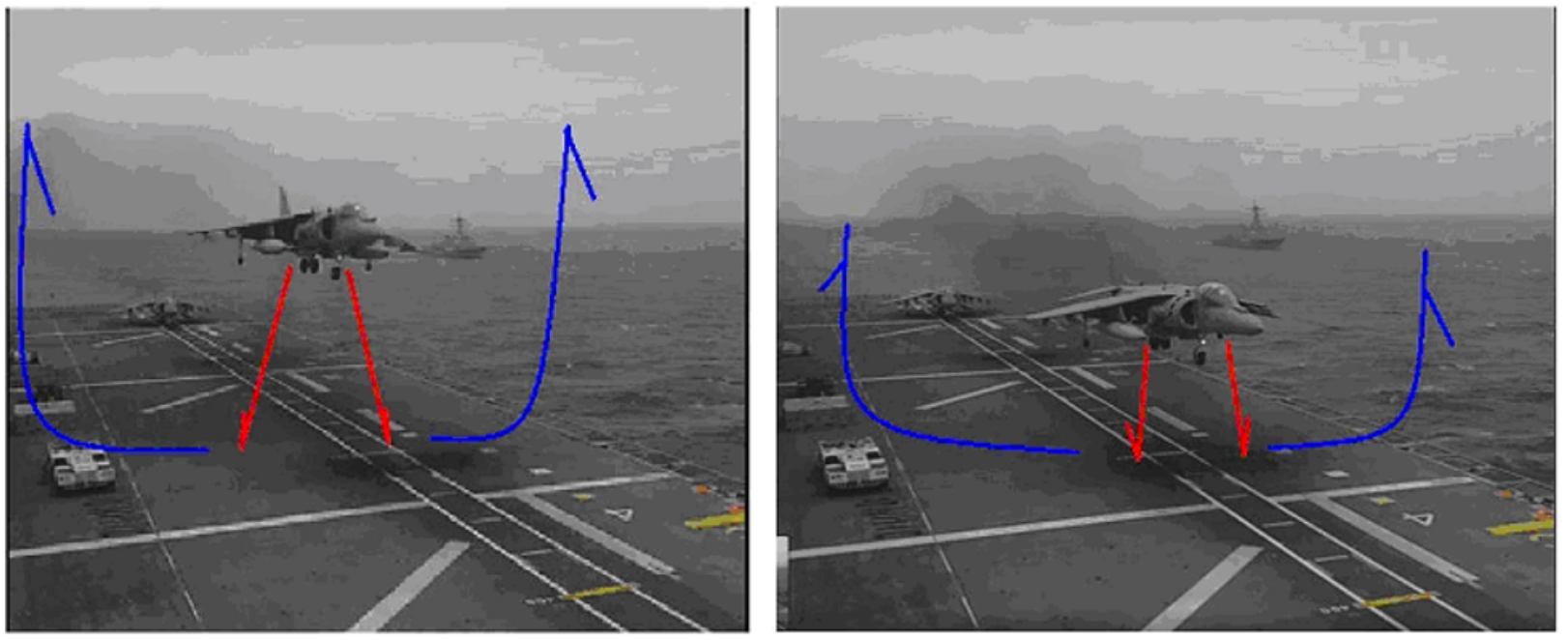

\section{Conclusions}

This research work began with an in-depth analysis of the problem of L.E. erosion on the airfoil profiles of the compressor under examination. In fact a rigorous study of the erosion mechanism caused by an impact of a particle flow with the airfoil profile surface was carried out. All the parameters characteristic of efflux were tested in similitude conditions on the Water Table Test Bench except for the physical dimensions of the particles used in the tests. They were 
not included in this current experiment because of the above mentioned problems with the water flow release and correct representation of the particle-blade interaction. Apart from this, the mathematical representation of the model of interaction was reproduced on the Water Table and the experimental determination of the lift coefficients was carried out using analytical reports derived from Lamb's Theory with modifications suggested by extensive experience in the study of efflux on the Water Table. This was also confirmed by numerical studies and the large scientific literature cited. The rigorous mathematical formulation of the problem examined has facilitated a more detailed analysis of the results obtained, as the prediction of impact was verified in laboratory conditions making it possible to reproduce a close approximation of the interactions which actually occur. The results obtained regarding the decrease in aerodynamic performance of the profiles due to erosion, in the light of the mathematical framework of the problem, confirm the statistics taken from scientific literature and from the maintenance reports on the engines. The mathematical framework of the type of interaction and the results of the experiment, far from being merely descriptive (they were in fact obtained and not only as order of magnitude of the performance), enabled us to obtain guidance on the improvement of maintenance techniques aimed at maintaining high aerodynamic performance of the cascade and of the single airfoil profiles. The conditions of fouling and erosion may be realised as during the arrival phase on the deck of an aircraft carrier, as in the case of an HARRIER. The corresponding action of particles on blade surface have been analysed. Work carried out has shown how restoring in similitude conditions is better than with a grinding machine but, apart from being more expensive, it can also be used fewer times because of the obvious reduction in the length of the profiles' chords. Therefore the restoration is only applicable once before replacing the worn blade, while the grinder can be used three or four times, giving the advantage of a longer life for the engine parts. Once again the usefulness of the Water Table has been shown for easily obtaining good cost effective results. In the near future, plans have been made to verify the results obtained testing the profiles in wind tunnels, while extending and improving the tests by using suitable tracers to increase our knowledge of the interaction between the flow of particles and the surface of the blade. First and foremost however, attempts will be made to improve the modelling of the particles used as tracers by scaling them down to the proper size.

\section{Acknowledgments}

The Author would like to thank Salvatore Pompei, Domenico Gentile and Lorenzo Concia, who built the airfoil profiles used in these tests with great expertise and skill. Finally, a sincere tribute must be paid to the fond memory of Professor Carmelo Caputo for his commitment to using the Water Table at the then 'Istituto di Macchine e Tecnologie' (now the 'Dipartimento di 
Ingegneria Meccanica e Aerospaziale') and who, on more than one occasion, encouraged its use for in-depth research into efflux through the cascade of turbo engines. The Author deepest thanks go to him for his generous and unparalleled teaching which never failed to motivate his disciples. And not last, a special thanks to the friend and colleague Prof. Alessandro Corsini.

\section{References}

[1] Aker, G.F. et al. (1989):"Preditcting Gas Turbine Degradation Due to Compressor Falling Using Computer Simulation Techniques", in Trans of the ASME, J. of Eng. for Gas Turbine and Power, vol. 111, pp. 343-350;

[2] A.M.C. (1992): RD-305 process, Extract, Compton, Airfoil Managemement Company.

[3] Aquaro, D. (2004): "Erosion of high temperature resistant materials due to impact of solid particulate: comparison between theoretical and numerical methods", in Proc. of the AIMETA Int. Tribology Conference, 14-17 September 2004, Rome, pp. 259-268;

[4] Armesto, C. et al. (eds.) (1993): GE Aircraft Engines - CF6-50 Performance Restoration at a Glance, booklet revisione 1, BIC 4484P (3/93), Cincinnati (Ohio)General Electric Co.;

[5] Batcho, P. F. et al. (1987):"Interpretation of Gas Turbine Response Due to Dust Ingestion", in Trans. of the ASME, J. of Eng. for Gas Turbine and Power, July '87, vol. 109,pp 344-352;

[6] Boynton, S.L. et al. (1993): "Investigation of Rotor Blade Roughness Effects on Turbine Performance" in Trans. of the ASME, J. of Turbomachinery, vol. 1115, July 1993, pp. 614-620;

[7] Calvert, W. (1994): "Prevent damage to gas turbines from ice ingestion", in Power, Oct.'94, pp. 73-75;

[8] Chow, Ronald et al. (1995): "Coatings Limit Compressor Fouling", in Turbomachinery International Journal, feb. '95, pp. 34-36;

[9] Damonte, N. (1994): "Il problema energetico nei trasporti aerei commerciali: innovazioni tecniche in atto e progetti per gli anni 2000", in Trasporti e Trazione, n5, ottobre '94, pp. 226234;

[10] De Pratti, G.M. - Arrighetti, C. (2009): "Analisi sperimentale del decadimento per erosione e fouling delle prestazioni di compressori assiali aeronautici", in Proc. of the ATI Congress at Montesilvano, pp. 9;

[11] Ericsson, L. E. (1980): "Karman Vortex Shedding and the effect of body motion", in AIAA Journal, Article n ${ }^{\circ} 79-1531 \mathrm{R}$, vol. 18, $\mathrm{n}^{\circ}$ 8, aug. '80, pp. 935-944;

[12] Eroglu, H et al. (1990): "Effect of Inlet Flow Angle on the Erosion of Radial Turbine Guide Vanes", in Trans. of the ASME, J. of Turbomachinery, Jan. '90, vol. 112, pp. 64-70;

[13] Kurz, R. - Brun, K. (2012): Fouling Mechanism in Axial Compressors, J. Eng. Gas Turbine Power, Mar. 2012, 134(3): 032401, pp. 9;

[14] Lakshminarasimha, A. N. et al. (1994):"Modeling and Analysis of Gas Turbine Performance Deterioration", in Trans. of the ASME, J. of Gas Turbine and Power, Jan. '94, vol. 116, pp. 46-52;

[15] Metwally, M. et al. (1995): "Blade Erosion in Automotive Gas Turbine Engine", in Trans. of the ASME, J. of Eng. for Gas Turbines and Power, vol. 117, Jan. 95, pp. 213-219;

[16] Natole, R. (1995): "Gas Turbine Components-Repair or Replace", in IGTI Global Gas Turbine News, May/June '95, pp. 4-7;

[17] Orlin, J. W. et al. (1947) : "Application of the Analogy between Water Flow with a Free Surface and Two-Dimensional Compressible Gas Flow”, NACA Report n 875, pp. 18; 
[18] Paoli, R. - Shariff, K. (2003): "Particle size distributions in atmospheric clouds", in Ann. Research Briefs 2003, NASA-Center for Turbulence Research, Moffett Field, pp. 39-47;

[19] Page, G. J. et Al. (2007) : Large Eddy Simulation of a Harrier Aircraft at Touch Down, in AIAA 2007-4294, pp. 12;

[20] Ramsden, K. W. (2006): Axial Compressor design and performance, Course Notes 2006, Cranfield University (UK);

[21] Soares, C. (2015): Inlet Angle in Compressor, in Gas Turb ines, 2nd Ed., pp. 15;

[22] Tabakoff, W. et al. (1990):"Simulation of Compressor Performance Deterioration Due to Erosion", in Trans. of the ASME, J. of Turbomachinery, Jan. '90, vol. 112, pp. 78-83;

[23] Taylor, R. P. (1990):"Surface Roughness Measurements of Gas Turbine Blades", in Trans. of the ASME, J. of Turbomachinery, April '90, vol.112, pp. 175-180. 